\title{
Effect of doxorubicin and cyclophosphamide regimen versus taxane on liver enzymes in Iraqi women with breast cancer.
}

\author{
Zainab NH Anber* \\ Department of Therapeutics and Clinical Pharmacy, Baghdad College for Medical Sciences, Iraq
}

\begin{abstract}
Objective: To investigate the effect of doxorubicin, cyclophosphamide and taxane chemotherapy on the liver enzymes in Iraqi women with breast cancer.

Methods: This cohort prospective study was carried out at the Biochemistry Department, College of Medicine, University of Baghdad and at the Oncology Clinic, Oncology Teaching Hospital, Baghdad, Iraq. It included 56 women with regular menstrual cycle $(25-45$ y) who were newly diagnosed with breast cancer. The women were classified into 3 groups: GI (pre-treatment): 29 women with breast cancer before starting chemotherapy and the post treatment group: the same 29 women of GI (pretreatment) who finished 4 cycles of anthracycline chemotherapy (course 1), and GII: which involved another 27 women who had finished both courses of chemotherapy, (course 1) and 4 cycles of taxanes (course 2), serum alanine aminotransferase (ALT), serum aspartate aminotransferase (AST), serum alkaline phosphatase (ALK) and serum total proteins were measured using colorimetric methods.

Results: Concerning the liver biochemical parameters (ALT and AST); there was no significant difference between GII and both GI (pre-treatment and post treatment) groups. While the serum levels of these enzymes increased significantly in GI (post treatment) compared to the (pre-treatment) group. According to the serum ALP; there was no significant difference between all groups. While the serum TP shows a significant increase in GI (post treatment) compared to the (pre-treatment) group. And a highly significant increase in GII compared to both GI (pre-treatment and post treatment) groups.

Conclusion: Breast cancer chemotherapeutic agents' combinations cause hepatic toxicity indicated by changes in liver enzymes levels and activity.
\end{abstract}

Keywords: ALT, AST, ALK, Breast cancer, Hepatotoxicity, Total proteins.

Accepted on December 26, 2018

\section{Introduction}

Breast carcinoma is one of the most popular neoplasms in women and is a major cause of deaths in the world [1]. In Iraq, it is the first cancer in ranking diagnosed in women [2]. The rate of breast cancer increased between the age of 60 to $69 \mathrm{y}$ [3]. Organ dysfunction is the most common in occurrence and the hepatic dysfunction is the most important one [4]. The liver damage occurred during chemotherapy may be due to antiemetics, antibiotics, analgesics used and not only due to anticancer therapy. Also, it may be caused by a previous condition such as infections (hepatitis), malnutrition, or suppression of immunity. So, it is not the toxic reaction the only cause $[5,6]$. Most of the hepatotoxic reactions are due to variation in the metabolism or due to immunologic reactions and therefore they are idiosyncratic and do not depend on the dose of the drug nor can be predictable [7]. Usually hepatotoxicity can produce serious reactions such as fibrosis, steatosis, cholestasis, necrosis and vascular injury [8]. Anthracycline (doxorubicin) is widely used to treat breast cancer. Although it can produce many side effects such as hepatotoxicity, cardiotoxicity, testicular toxicity and hematological toxicity [9]. Doxorubicin metabolism is extensively carried out in the liver through the antioxidant mechanisms mainly the glutathione pathway [10]. While cyclophosphamide metabolism is carried out through the cytochrome P450 system in the liver which converts cyclophosphamide to 4-hydroxy cyclophosphamide which is in equilibrium with aldophosphamide (the tautomeric form) of the drug. In cytolysis; it can be cleaved non-enzymatically into phosphoramide and acrolein. Which are both highly cytotoxic. In spite of its hepatic metabolism; only few studies reported elevated liver enzymes and thus its hepatotoxicity is due to an idiosyncratic reaction and not due to direct toxicity [11-13]. While paclitaxel (Taxol) and docetaxel (Taxotere) which are microtubule inhibiters are mainly metabolized by the liver and are restricted in patients with liver diseases [14].

Only few studies had investigated the associations of liver function tests with chemotherapy in breast cancer. The liver function tests measured the levels of important parameters including liver aminotransferases (ALT, AST), ALK and serum total proteins. Thus, the aim of the present study was to assess 
the effect of chemotherapeutic agents on the liver enzymes in patients with breast cancer.

\section{Subjects and Methods}

This study was carried out at the Biochemistry Department, College of Medicine, University of Baghdad and at the Oncology Clinic at Oncology Teaching Hospital during the period from May 2018 to October 2018. It included 56 women who were already newly diagnosed by oncology group to have breast cancer. Their age range (25-45 years). The study design included; group I; pre-treatment (GI; pre-treatment); twenty nine women newly diagnosed with breast cancer before starting chemotherapy. Group I; posttreatment (GI; post treatment): the same twenty nine women of the pretreatment group who finished 4 cycles of anthracycline (Doxorubicin 60 $\mathrm{mg} / \mathrm{m}^{2}$ and cyclophosphamide $600 \mathrm{mg} / \mathrm{m}^{2}$ ) chemotherapy. And group II (GII): which involved another twenty seven women who were already finished both courses of chemotherapy, including (course 1 and 4 cycles of taxanes (Docetaxel) 100 $\mathrm{mg} / \mathrm{m}^{2}$ (course 2). All included women were subjected for imaging investigations including X-ray, ultrasound study, and if necessary computed tomography (C.T) scan and/or MRI in order to rule out invaded cancer in liver, bones and other sites of body. So, ensuring the absence of liver metastasis in all the involved women. Exclusion criteria included pregnant woman, chronic diseases (D.M, hypertension), alcoholic and smokers. Also, women consuming anti-inflammatory drugs. Formal consent was taken from each woman (verbal and written). We received ethical approval from the Scientific Committee of the Biochemistry Department, College of Medicine, University of Baghdad, Iraq. Five milliliters of venous blood were taken from each individual at time 8:00-11:00 a.m. Blood samples were collected in serum-separating tubes which allowed to clot at room temperature for thirty minutes, then the samples were centrifuged at $(2000 \mathrm{Xg})$ for 10 minutes, the obtained serum was frozen at $-20^{\circ} \mathrm{C}$ till the time of measurement. The level of enzymes (ALT, AST, ALK) and the total serum proteins were analysed using commercial kits. All material kits for the measured parameters were provided from Human $\mathrm{GmbH}$. 65205 Wiesbaden, Germany. The Statistical Package for Social Sciences (SPSS) version 23 (SPSS Inc., Chicago, IL., USA), and Minitab analysis programs were used for all statistical studies. ANOVA and Student's t-tests were used to test for statistical significance. Linear regression was utilized to test for correlation between different studied parameters, and the significance of the $\mathrm{r}$-value was assessed by related t-test. Pvalues of less than 0.05 were considered significant.

\section{Results}

\section{Clinical}

The clinical data in Table 1 shows that the difference in (mean \pm SEM) value of the age was not significant between GI (38.79 $\pm 0.91)$ and GII $(39.59 \pm 0.95)$. Also, there was no significant difference in BMI values between GI (30.04 \pm 0.94$)$ and GII $(31.78 \pm 1.24)$.

Table 1. The (mean \pm SEM) values of the age and body mass index (BMI) between GI (pretreatment), GI (post treatment) and GII.

\begin{tabular}{llll}
\hline & $\begin{array}{l}\text { GI; pretreatment } \\
(\mathbf{n}=29)\end{array}$ & $\begin{array}{l}\text { GI; } \\
\text { treatment }(\mathbf{n}=29)\end{array}$ & \multicolumn{1}{c}{ post } \\
& $38.79 \pm 0.91$ & $38.79 \pm 0.91$ & $39.59 \pm 0.95$ \\
\hline Age $(\mathrm{y})$ & $30.04 \pm 0.94$ & $30.04 \pm 0.94$ & $31.78 \pm 1.24$ \\
\hline $\mathrm{BMI}\left(\mathrm{kg} / \mathrm{m}^{2}\right)$ & & & \\
\hline
\end{tabular}

ANOVA test reveals a non- significant difference between groups (NS)

\section{Biochemical}

Concerning the liver biochemical parameters (ALT and AST); there was no significant difference between GII and both GI (pretreatment and post treatment) groups. While the serum level of these enzymes increased significantly $(p<0.05)$ in GI (post treatment) compared to GI (pretreatment). According to the serum ALP; there was no significant difference between all groups. While the serum TP shows a significant $(p<0.05)$ increase in GI (post treatment) compared to GI (pretreatment). And a highly significant $(p<0.001)$ increase in GII compared to both GI (pretreatment and post treatment) groups. The normal reference range for ALT and AST is (up to $12 \mathrm{IU} / \mathrm{L}$ ). For ALK.is (32-92 IU/L) and for total proteins is $(6.6-8.7 \mathrm{gm} / \mathrm{dl})$ as shown in Table 2 .

Table 2. The (mean \pm SEM) values of the serum AST, ALT, ALK and $T P$ in GI (pretreatment), GI (post treatment) and GII.

\begin{tabular}{llll}
\hline Parameter & GI (pretreatment) & GI (post treatment) & GII \\
\hline ALT IU/L & $6.68 \pm 0.91$ & $10.44 \pm 1.00^{* a}$ & $7.88 \pm 2.25$ \\
\hline AST IU/L & $5.44 \pm 0.76$ & $11.41 \pm 2.04^{* a}$ & $8.77 \pm 1.37$ \\
\hline ALK IU/L & $86.32 \pm 4.16$ & $79.07 \pm 3.48$ & $83.25 \pm 4.23$ \\
\hline TP g/dl & $6.48 \pm 0.12$ & $7.7 \pm 0.3^{* a}$ & $9.87 \pm 0.4^{* * a}$ \\
\hline
\end{tabular}

Data are expressed as (mean \pm SEM). Values with different superscripts are significantly different: ${ }^{*} \mathrm{p}<0.05$ significant; ${ }^{* *} \mathrm{p}<0.001$ highly significant.

The present study had shown that in GI (pretreatment); there was a significant positive correlation between BMI and serum ALK; $\quad(r=0.378), \quad(p<0.05)$. Also, a significant positive correlation between age and serum ALK; $(\mathrm{r}=0.430),(\mathrm{p}<0.05)$. Also, in GI (post treatment); there was a significant positive correlation between serum ALT and serum ALK; $(r=0.440)$, $(\mathrm{p}<0.05)$. And, a highly significant positive correlation between serum AST and serum ALK; $(r=0.561),(p<0.01)$. While in GII; there was a highly significant positive correlation between serum ALK and serum ALT; $(r=0.554),(p<0.01)$.

\section{Discussion}

In the present study, there was no significant difference in the age and BMI between women's group (Table 1). The (mean \pm SEM) age of women of (G1; pretreatment) of the present study was $(38.79 \pm 0.91)$. Jemal et al. found that $25 \%$ of breast 
cancer cases were before menopause [15]. This is in association with the present study as the age of patients was between 25-45 y. Also, the clinical characteristics of patients of the present study showed that the breast cancer women were overweight and obese. Several studies had concluded that the obesity is a risk factor to breast cancer and other types of cancer. To decrease the risk of breast cancer recurrence and death, the obese breast cancer patients need to lose their weight $[16,17]$.

The present study shows an increase in the serum AST and ALT in GI (post treatment) compared to GI (pretreatment), (Table 2); these results were in congruence with Sathesh et al. who showed that doxorubicin administration cause tissue damage and an increase of enzymes membrane leakage of these enzymes [18]. Also, the present study was in agreement with Damodar et al. who revealed that the incidence of hepatotoxicity in patients treated with doxorubicin injection was $30.4 \%$ [19]. Yang et al. stated that about $40 \%$ of patients suffered liver damage after doxorubicin treatment [20]. This was supported with a study by Llesuy and Arnaiz who stated that doxorubicin administration produced increases of $51 \%$ and $53 \%$ in liver spontaneous chemiluminescence and malonaldehyde formation; respectively. The main characteristics of these processes were elevations in serum levels of ALT, AST and bilirubin [21]. The underlying mechanism is that doxorubicin causes an increase in the malonaldehyde levels together with a decrease in the serum levels of superoxide dismutase and catalase activity through the one-electron reduction of nicotinamide adenine dinucleotide phosphate (NADPH) cytochrome P-450 reductase enzyme [22,23]. Previous studies reported that administration of antioxidants such as vitamin E, C, and A could reduce the hepatotoxic effect of doxorubicin. And that both virgin olive oil and selenium could be given as dietary supplements with the appropriate concentration and dosage form to maximize the antitumor action of these agents and to minimize the hepatotoxic effect of doxorubicin [24,25].

Also the results of this study was consistent with that recorded by Tomoki et al., who found that doxorubicin elevates plasma AST and ALT activities in mice [26]. Other study established that there was close correlation between the administration of doxorubicin and the appearance of hepatic dysfunction [27]. Chauhan et al. found that the levels of these enzymes were increased but still within the normal reference ranges during the different courses of chemotherapy this was explained by the progressive liver damage caused by the chemotherapeutic drugs [28].

The present study showed that there was a non-significant difference in the serum levels of alkaline phosphatase breast cancer patients and patients treated with chemotherapy. These results were on the same line with a study done by Oluboyo et al. who stated that there was no statistically significant difference in the ALP activity between the breast cancer subjects on chemotherapy and those not on chemotherapy, It has been reported that chemotherapeutic agents can have both direct and indirect effects on the bone microenvironment ultimately leading to a decrease in the bone mineral density [29]. Also, the present study was in agreement with other studies in which they didn't find any significant difference in ALP levels in non-metastatic breast cancer [30,31]. On the other hand the present results were in contrary to previous studies in which they stated that the progressive increase in serum ALP was due to metastasis of breast cancer either to bone or liver [32,33]. Also, inconsistent with previous studies in which they stated that chemotherapy induce bone marrow density loss [34,35].

The results of the significant increase in the serum total proteins seen in the chemotherapy treated group rather than patients without chemotherapy were inconsistent with Chaun et al. results that showed that there was a non-significant change in the level of total proteins [28]. This fact can be explained by the decrease in the serum level of albumin through catabolism and increase in the serum level of globulins through synthesis [36]. And thus they had proposed that the serum levels of these proteins should be considered individually and not the amount of the total protein levels [37].

The significant positive correlation between BMI and serum ALK in GI (pretreatment) was in agreement with that observed by Khan et al. who stated that higher amounts of ALK were linked to obesity since adipocytes are good source for ALK isoenzymes [38]. Concerning the positive correlation between age and serum ALP; there was no previous studies explained this association in breast cancer. But, it was reported that increased overexpression of serum ALP was observed with increased aggressiveness of the disease [39].

\section{Conclusion}

The altered liver function tests caused by the chemotherapeutic agents used to treat breast cancer may cause an increased risk of hepatic toxicity.

\section{References}

1. Polyak K. On the birth of breast cancer. Biochim Biophys Acta 2001; 1552: 1-13.

2. Arkan OJ. Breast cancer in Western Iraq: clinicopathological single institution study. Adv Breast Cancer Res 2016; 5: 83-89.

3. Al-Hashimi MM, Wang XJ. Breast cancer in Iraq, incidence trends from 2000-2009. Asian Pac J Cancer Prev 2014; 15: 281-286.

4. Superfin D, Lannucci AA, Davies AM. Commentary: oncologic drugs in patients with organ dysfunction: a summary. Oncologist 2007; 12: 1070-1083.

5. Benichou C. Criteria of drug-induced liver disorders: report of an international consensus meeting. J Hepatol 1990; 11: 272-276.

6. Maria VA, Victorino RM. Development and validation of a clinical scale for the diagnosis of drug-induced hepatitis. Hepatology 1997; 26: 664-669.

7. Lee WM. Drug-induced hepatotoxicity. N Engl J Med 1995; 333: 1118-1127. 
8. Ishak KG, Zimmerman HJ. Morphologic spectrums of drug-induced liver disease. Gastroenterol Clin North Am 1995; 24: 759-786.

9. Hardenbergh PH, Recht A, Gollamudi S, Come SE, Hayes DF, Shulman LN, ONeill A, Gelman RS, Silver B and Harris JR. Treatment-related toxicity from a randomized trial of the sequencing of doxorubicin and radiation therapy in patients treated for early stage breast cancer. Int J Radiat Oncol Biol Phys 1999; 45: 69-72.

10. Meredith MJ, Reed DJ. Depletion in vitro of mitochondrial glutathione in rat hepatocytes and enhancement of lipid peroxidation by adriamycin and 1, 3 chloroethyl-nitrosurea (BCNU). Biochem Pharmacol 1983; 32: 1383-1388.

11. Goldberg JW, Lidsky MD. Cyclophosphamide associated hepatotoxicity. South Med J 1985; 78: 222-223.

12. Snyder LS, Heigh RL, Anderson ML. Cyclophosphamide induced hepatotoxicity in a patient with Wegeners granulo- matosis. Mayo Clin Proc 1993; 68: 1203-1204.

13. Shaunak S, Munro JM, Weinbren K, Walport MJ, Cox TM. Cyclophos- phamide induced liver necrosis: a possible interaction with azathioprine. Q J Med New Series 1988; 252: 309-317.

14. Huizing MT, Misser VH, Pieters RC, ten Bokkel Huinink WW, Veenhof $\mathrm{CH}$, Vermorken JB, Pinedo HM, Beijnen JH. Taxanes: a new class of antitumor agents. Cancer Invest 1995; 13: 381-404.

15. Jemal A, Tiwari RC, Murray T, Ghafoor A, Samuels A, Ward E, Feuer EJ, Thun MJ. Cancer statistics. CA Cancer J Clin 2004; 54: 8-29.

16. Chan DS, Vieira AR, Aune D, Bandera EV, Greenwood DC, McTiernan A, Navarro Rosen-blatt D, Thune I, Viera $\mathrm{R}$, Norat T. Body mass index and survival in women with breast cancer-systematic literature review and metaanalysis of 82 follow-up studies. Ann Oncol 2014; 10 : 1901-1914.

17. Goodwin PJ. Obesity and breast cancer outcomes: how much evidence is needed to change practice? J Clin Oncol 2016; 34: 646-648.

18. Sathesh KV, Sharmila S, Premkumar T, Palanisamy K, Jagan S, Devaki T. Protective effect of umbelliferone against doxorubicin induced cardiotoxicity in wistar albino rats. Sci Technol 2016; 2: 90-98.

19. Damodar G, Smitha T, Gopinath S, Vijayakumar S, and Rao YA. An evaluation of hepatotoxicity in breast cancer patients receiving injection doxorubicin. Ann Med Health Sci Res 2014; 4: 74-79.

20. Yang XL, Fan CH, Zhu HS. Photo-induced cytotoxicity of malonic acid C (60) fullerene derivatives and its mechanism. Toxicol in vitro 2002; 16: 41-46.

21. Llesuy SF, Arnaiz SL. Hepatotoxicity of mitoxantrone and doxorubicin. Toxicology 1990; 63: 187-198.

22. Lee V, Randhawa AK, Singal PK. Adriamycin-induced myocardial dysfunction in vitro is mediated by free radicals. Am J Physiol 1991; 261: 989-995.
23. Kalender Y, Yel M, Kalender S. Doxorubicin hepatotoxicity and hepatic free radical metabolism in rats. The effects of vitamin E and catechin. Toxicology 2005; 209: 39-45.

24. Chen Y, Jungsuwadee P, Vore M, Butterfield DA, St Clair DK. Collateral damage in cancer chemotherapy: Oxidative stress in non-targeted tissues. Mol Interv 2007; 7: 147-156.

25. Granados-Principal S, Quiles JL, Ramirez-Tortosa CL, Sanchez-Rovira P, Ramirez-Tortosa MC. New advances in molecular mechanisms and the prevention of adriamycin toxicity by antioxidant nutrients. Food Chem Toxicol 2010; 48: 1425-1438.

26. Tomoki K, Isami F, Norio I. Metallothionein Acts as a cytoprotectant against doxorubicin toxicity. Pharmacol Exp Ther 2000; 292: 299-302.

27. Aviles A, Herrera J, Ramos E, Ambriz R, Aguirre J, Pizzuto J. Hepatic injury during doxorubicin therapy. Arch Pathol Lab Med 1984; 108: 912-913.

28. Chauhan P, Yadav R, Kaushal V, Beniwal P. Evaluation of serum biochemical profile of breast cancer patients. Int J Med Res Health Sci 2016; 5: 1-7.

29. Oluboyo AO, Oduikolo CV, Oluboyo BO, Ihim AC, Ikechukwu CK Emegoakor CD, Chianakwanam GU. Assessment of Bone minerals and alkaline phosphatase activity in Breast cancer subjects. J Dent Med Sci 2015; 14: 44-46.

30. Vanhoof VO, Vanoostrom AT, Lepoutre LG, DeBroe ME. Alkaline phosphates isoenzyme patterns in malignancy disease. Clin Chem 1992; 38: 2546-2451.

31. Stieber P, Mangal D, Ritzke C, Rossler N, Kirsch CM, Eiermann W. Signi?cance of bone alkaline phosphatase, CA15-3 and CEA in detection of bone metastasis during follow up of patients suffering from breast carcinoma. Eur J Clin Chem Clin Biochem 1992; 30: 809-814.

32. Ramaswamy G, Rao VR, Krishnamoorthy L, Ramesh G, Gomathy R, Renukadevi D. Serum levels of bone alkaline phosphatase in breast and prostate cancer with bone metastasis. Indian J Clin Biochem 2000; 15: 110-113.

33. Mishra S, Sharma DC, Sharma P. Studies of biochemical parameters in breast cancer with and without metastasis. Indian J Clin Biochem 2004; 19: 71-75.

34. Michaud LB, Goodin S. Cancer-treatment-induced bone loss, part 1. Am J Health Sys Pharm 2006; 63: 419-430.

35. Nishio KT, Maruoka A, Nakamura R, Takai K, Sekijima M, Tunetoh T, Terai SY, Ohmichi M. Bone mineral loss induced by anticancer treatment for gynecological malignancies in premenopausal women. Endocr Connect 2013; 2: 11-17.

36. Joudi ALFS. Prognostic value of an index for serum globulin compensation in colon and breast cancers. Singapore Med J 2005; 46: 710-713.

37. Degowin RL, Leblond RF. and Brown DD. DeGowins diagnostic examination (8th Edn.). McGraw Hill Professional Publishers 2004; 948-959. 
Effect of doxorubicin and cyclophosphamide regimen versus taxane on liver enzymes in Iraqi women with breast cancer

38. Khan AR, Awan FR, Najam SS, Islam M, Siddique T, Zain M. Elevated serum level of human alkaline phosphatase in obesity. J Pak Med Assoc 2015; 65: 1182-1185.

39. Abdul KS, Shaham B, Zeenath J, Sarita P, Maqbool A, Azhar RH, Fouad AD, Asma T, Dahish A, Khawla SAK. ALK alteration is a frequent event in aggressive breast cancers. Breast Cancer Res 2015; 17: 127.

\section{*Correspondence to}

Zainab N. H. Anber

Department of Therapeutics and Clinical Pharmacy

Baghdad College for Medical Sciences

Iraq 